\title{
Is School Gardening Combined with Physical Activity Intervention Effective for Improving Childhood Obesity? A Systematic Review and Meta-Analysis
}

\author{
Yufei Qi ${ }^{1,2} \mathbb{D}$, Sareena Hanim Hamzah ${ }^{1}$, Erya Gu ${ }^{3}$, Haonan Wang ${ }^{2}$, Yue Xi ${ }^{4} \mathbb{D}$, Minghui Sun ${ }^{4}$, Siyu Rong ${ }^{5}$ \\ and Qian Lin ${ }^{4, *(D)}$ \\ 1 Centre for Sport and Exercise Sciences, Universiti Malaya, Kuala Lumpur 50603, Malaysia; \\ yufeiqi@csu.edu.cn (Y.Q.); sareena@um.edu.my (S.H.H.) \\ 2 Department of Physical Education and Research, Central South University, 932 Lushan South Rd., \\ Changsha 410083, China; haonanwangcsu@csu.edu.cn \\ 3 School of Foreign Languages, Central South University, 932 Lushan South Rd., Changsha 410083, China; \\ 8106180507@csu.edu.cn \\ 4 Department of Nutrition Science and Food Hygiene, Xiangya School of Public Health, \\ Central South University, 110 Xiangya Rd., Changsha 410078, China; xiyue0404@csu.edu.cn (Y.X.); \\ sun.1234@csu.edu.cn (M.S.) \\ 5 Graduate School, Wuhan Sports University, Wuhan 430079, China; s2024654@siswa.um.edu.my \\ * Correspondence: linqian@csu.edu.cn; Tel.: +86-138-7482-0173
}

check for updates

Citation: Qi, Y.; Hamzah, S.H.; Gu, E.; Wang, H.; Xi, Y.; Sun, M.; Rong, S.; Lin, Q. Is School Gardening Combined with Physical Activity Intervention Effective for Improving Childhood Obesity? A Systematic Review and Meta-Analysis. Nutrients 2021, 13, 2605. https://doi.org/ $10.3390 /$ nu13082605

Academic Editor: Pascale Duche

Received: 6 July 2021

Accepted: 26 July 2021

Published: 28 July 2021

Publisher's Note: MDPI stays neutral with regard to jurisdictional claims in published maps and institutional affiliations.

Copyright: (c) 2021 by the authors. Licensee MDPI, Basel, Switzerland. This article is an open access article distributed under the terms and conditions of the Creative Commons Attribution (CC BY) license (https:// creativecommons.org/licenses/by/ $4.0 /)$.

\begin{abstract}
School gardening activities (SGA) combined with physical activities (PA) may improve childhood dietary intake and prevent overweight and obesity. This study aims to evaluate the effect of SGA combined with PA on children's dietary intake and anthropometric outcomes. We searched studies containing randomized controlled trials up to January 2021 in Web of Science, PubMed, Cochrane Library, and the EBSCO database on this topic for children aged 7 to 12 years. Fourteen studies met the requirements for meta-analysis $(n=9187)$. We found that SGA has no obvious effect on improving children's BMI (WMD $\left.=-0.49 ; p=0.085 ; \mathrm{I}^{2}=86.3 \%\right)$, BMI z-score (WMD = -0.12 ; $\left.p=0.235 ; \mathrm{I}^{2}=63.0 \%\right)$, and $\mathrm{WC}\left(\mathrm{WMD}=-0.98 ; p=0.05 ; \mathrm{I}^{2}=72.9 \%\right)$. SGA can effectively improve children's FVs (WMD $=0.59, p=0.003, \mathrm{I}^{2}=95.3 \%$ ). SGA combined with PA can significantly increase children's FVs but cannot greatly improve weight status. Although more studies on this topic are needed to prove the effectiveness of this method, the results of our review show that both SGA and SGA combined with PA has a modest but positive impact of reducing BMI and WC outcomes but can significantly increase children's FVs.
\end{abstract}

Keywords: physical activity; school gardening activity; childhood obesity; meta-analysis; systematic review

\section{Introduction}

Childhood obesity is a public health priority and its prevalence and economic burden have been steadily increasing worldwide [1,2]. In the past three decades, the detection rate of childhood obesity in the United States has tripled, and the rate of adolescent obesity detection has increased by four times [3-5]. Related reports showed that in the past 20 years, the body mass index (BMI) of children and adolescents aged 6 to 17 in China has increased by $11.1 \%$ for overweight and $7.9 \%$ for obesity [6]. Childhood obesity is strongly associated with adult obesity [7-9]. It not only has an impact on children's physical and mental health, as well as their social abilities, but it is also the primary risk factor for metabolic syndrome, cardiovascular- and cerebrovascular-related chronic diseases [10-13], and death in adulthood [14].

Public institutions have developed and implemented several strategies to prevent obesity in children, including school gardening activities (SGA) and physical activities 
(PA). SGA, known as a "learning laboratory", is a way based on Social Cognitive Theory (SCT) to teach students' skills through fun hands-on activities, selecting the school as the intervention site and using gardening as a key component is a promising approach to addressing healthy eating and student's weight status [15-17]. In school gardens where students grow edible produce, they generally learn science and nutrition concepts relevant to growing food while they work in the garden, which enhances students' positive modeling of fruits and vegetables and increases their preference for these foods as well as their fruit and vegetable intakes (FVs) [18,19]. According to Molitor and Doerr [20], children who learn healthy eating habits at a young age are more likely to maintain these habits throughout their life. Children at a young age must develop healthy eating habits for their future health [21]. Some scholars have used SGA to successfully improve children's FVs and their intake preferences [22-24], but the opinions on the effects of SGA on weight are divided [25-28]. Scientific PA is an effective way to reduce BMI, body fat, and serum Chemerin in obese children, and also controls their blood pressure [29,30]. Short-term or long-term moderate-to-high intensity physical activity (MVPA) has been related to increased blood flow to the brain and neurotransmitter levels, as well as enhanced attention, motor skills, physical fitness, executive function, and social skills, and improved mental health in children [31-34]. Extracurricular PA is also considered closely during the study process, since the short time of school physical education may be occupied by other key courses $[35,36]$. However, the research shows that extracurricular PA has mixed effects on improving children's obesity [37-39]. Considering that each SGA and PA intervention was proven to be effective, theoretically, combining SGA with PA might improve children's eating habits and increase the amount of PA to reduce obesity more effectively.

BMI, body mass index z-score (BMI z-score), and WC are commonly used to measure anthropometric characteristics and stratify the risk for overweight and obesity in adults and children [40,41]. BMI and WC are easily obtainable and have proved to be strong predictors of metabolic syndrome, type 2 diabetes, and cardiovascular disease in adults and children [42]. Many scholars of the United States and other developed countries have used SGA to explore its impact on children's BMI and other anthropometric outcomes [43-45]. Therefore, we systematically reviewed and meta-analyzed the effects of SGA on anthropometric outcomes of school-age children (7-12 years old), gathering experimental information on BMI and WC changes in SGA and other interventions. Additionally, we undertook an SR on the impact of SGA and PA on the motivation and preference of fruits and vegetables and anthropometric outcomes of school-age children (7-12 years old). This work can provide clinicians, teachers, and policymakers with robust evidence on the efficacy of SGA combined with PA as a comprehensive intervention model to improve children's obesity, providing an important countermeasure to deal with childhood obesity.

\section{Materials and Methods}

\subsection{Databases and Search Criteria}

We performed a systematic search and review according to PRISMA guidelines [46]. We searched Web of Science, PubMed, Cochrane Library, and EBSCO databases to identify relevant studies as for January 2021. Additionally, the specifically designed search strings for this purpose were "obesity", "children", "school gardening", "physical activities", and "fruits and vegetables". W.H.N. and R.S.Y. completed the research process individually and in duplicate. Meeting and consultations with another author (Q.Y.F) solved any disagreements in these regards. Our research was registered in PROSPERO (CRD42021232858) on 28 March 2021.

\subsection{Study Selection}

Inclusion criteria were as follows: (1) children attending school, aged 7-12 years; (2) SGA and PA for obesity prevention; (3) only SGA or SGA combined with PA for intervention groups, only nutritional education or no intervention for control groups, and 
post-intervention outcomes including FVs, BMI, BMI z-score, and WC; and (4) randomized controlled trials (RCTs).

Exclusion criteria were as follows: (1) research on gardening activity outside school, (2) studies in which FVs outcomes were not recorded accurately by food intake diaries or Block Kids food filters, (3) only FVs as an outcome, and (4) repeated study.

\subsection{Data Selection and Extraction}

Two authors (W.H.N. and R.S.Y.) extracted data from the included studies for analysis, resolved any disagreement through discussion and reaching a consensus, or requested an opinion of a third author (Q.Y.F). The extracted outcomes included author, publication year, number of study participants, mean age, intervention measures, outcomes, study duration, etc.

\subsection{Study Quality Assessment}

Two authors (X.Y. and S.M.H.) evaluated the quality of the included studies using the Cochrane Collaboration Risk of Bias (ROB2.0) for assessing the risk of bias recommended. The Cochrane Tool allowed for analyzing the following groups: random sequence generation, allocation concealment, blinding of participants and personnel, blinding of outcome assessment, incomplete outcome data, selective reporting, and other (analysis for intention to treat and compliance). For each bias group, it was possible to assign a value of "high", "low", or "unknown" risk of bias when it was not specified if a specific bias was present or not. Any disagreements in the evaluation process were resolved by the third author (Q.Y.F.).

\subsection{Statistical Analysis}

We applied Stata 16.0 software to analyze the heterogeneity of studies and calculate the $\mathrm{I}^{2}$ statistic. If the $\mathrm{I}^{2}$ statistic was greater than $50 \%$, we utilized a random-effects model, otherwise a fixed-effects model was used. Outcome measures were merged with the effect value $Z$, the weighted mean difference (W.M.D.), and the confidence interval value $(95 \%$ CI). Results of the meta-analysis were visualized using forest plots, while the publication bias was assessed using funnel plot and Egger's test. We also conducted a sensitivity analysis of the combined results of $\mathrm{I}^{2}$ studies to find the sources of heterogeneity and corresponding reasons.

\section{Results}

\subsection{Search Findings}

Our search yielded 216 studies, among which 202 studies were retrieved by database browsing. We included 14 studies that met the eligibility criteria, 12 of which were appropriate for meta-analysis and 2 for review. Figure 1 shows the flowchart with the study selection process.

\subsection{Characteristics of the Included Studies}

All studies included designed SGA for primary school-age children. The duration of SGA ranged from 10 to 52 weeks. The total sample sizes ranged from 102 to 3153 children, among which most of the sample size ranged from 100 to 400 children. SGA provided opportunities for children to plant, water, weed, harvest, and taste various fruits and vegetables. Other interventions integrated activities, such as nutritional education, cooking activities, and participating in sports. The interventions included in the 14 studies can be divided into two types: one based on the SGA or GA only $(n=12)$, and one with an intervention including both SGA and PA $(n=2)$. Detailed studies' information are shown in Table 1. 


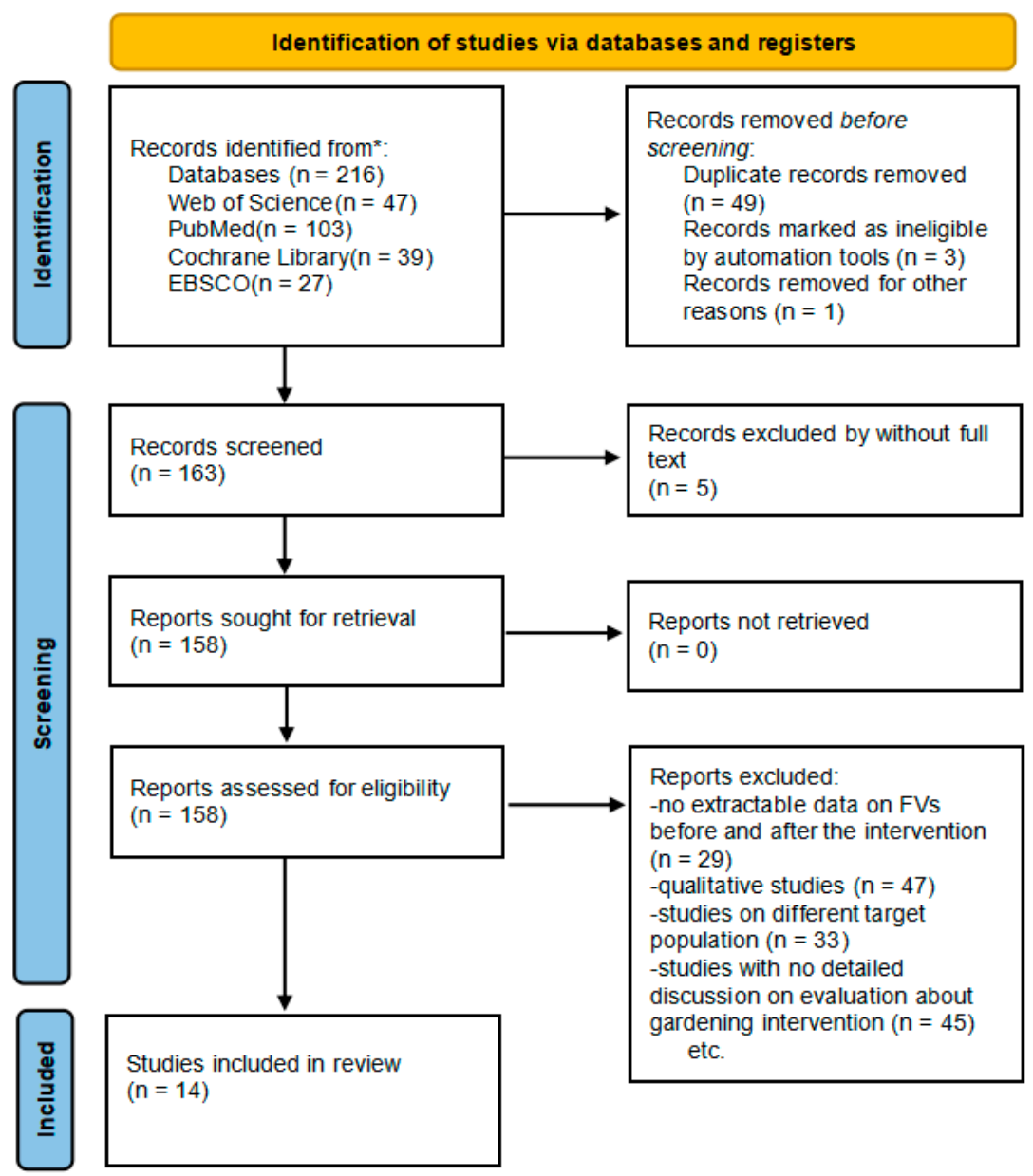

Figure 1. Flow diagram of studies selection. ${ }^{*}$ Consider, if feasible to do so, reporting the number of records identified from each database or register searched (rather than the total number across all databases/registers).

Table 1. Characteristics of the included studies.

\begin{tabular}{|c|c|c|c|c|c|c|c|c|}
\hline First Author & Year & $\begin{array}{l}\text { Sample } \\
\text { Size }\end{array}$ & Age & Interventions & $\begin{array}{c}\text { Study } \\
\text { Duration }\end{array}$ & $\begin{array}{l}\text { Control } \\
\text { Group }\end{array}$ & Outcomes & Results \\
\hline Davis [22] & 2011 & 114 & $7-12$ & Gardening & 12 weeks & $\begin{array}{c}\text { No } \\
\text { intervention }\end{array}$ & $\begin{array}{l}\text { BMIz } \\
\text { BMI } \\
\text { WC }\end{array}$ & $\begin{array}{c}\text { BMI } \downarrow \\
\text { BMIz } \downarrow \\
\text { WC } \downarrow\end{array}$ \\
\hline Christian [23] & 2014 & 641 & $7-11$ & Gardening & 72 weeks & $\begin{array}{c}\text { No } \\
\text { intervention }\end{array}$ & FVs & $\mathrm{FVs} \uparrow$ \\
\hline Ratcliffe [25] & 2011 & 320 & 12 & Gardening & 13 weeks & $\begin{array}{c}\text { No } \\
\text { intervention }\end{array}$ & FVs & FVs - \\
\hline Morgan [26] & 2010 & 127 & $11-12$ & Gardening & 10 weeks & $\begin{array}{c}\text { No } \\
\text { intervention }\end{array}$ & FVs & $\mathrm{FVs} \uparrow$ \\
\hline Gatto [27] & 2017 & 319 & $9-11$ & Gardening & 12 weeks & $\begin{array}{c}\text { No } \\
\text { intervention }\end{array}$ & $\begin{array}{l}\text { BMI } \\
\text { BMIz } \\
\text { WC }\end{array}$ & $\begin{array}{c}\text { BMI } \downarrow \\
\text { BMIz } \downarrow \\
\text { WC } \downarrow\end{array}$ \\
\hline Hanbazaza [47] & 2015 & 116 & $7-12$ & Gardening & 72 weeks & $\begin{array}{c}\text { No } \\
\text { intervention }\end{array}$ & FVs & $\mathrm{FVs} \uparrow$ \\
\hline Davis [48] & 2016 & 304 & $9-11$ & Gardening & 12 weeks & $\begin{array}{c}\text { No } \\
\text { intervention }\end{array}$ & BMI & $\mathrm{BMI} \downarrow$ \\
\hline Landry [49] & 2019 & 290 & $9-11$ & Gardening & 12 weeks & $\begin{array}{c}\text { No } \\
\text { intervention }\end{array}$ & $\begin{array}{l}\text { BMIz } \\
\text { WC }\end{array}$ & $\begin{array}{l}\text { BMIz } \downarrow \\
\text { WC } \downarrow\end{array}$ \\
\hline Martinez [50] & 2015 & 364 & $9-11$ & Gardening & 12 weeks & $\begin{array}{c}\text { No } \\
\text { intervention }\end{array}$ & WC & $\mathrm{WC} \downarrow$ \\
\hline
\end{tabular}


Table 1. Cont.

\begin{tabular}{|c|c|c|c|c|c|c|c|c|}
\hline First Author & Year & $\begin{array}{c}\text { Sample } \\
\text { Size }\end{array}$ & Age & Interventions & $\begin{array}{c}\text { Study } \\
\text { Duration }\end{array}$ & $\begin{array}{l}\text { Control } \\
\text { Group }\end{array}$ & Outcomes & Results \\
\hline Scherr [51] & 2018 & 409 & $9-10$ & Gardening & 48 weeks & $\begin{array}{c}\text { No } \\
\text { intervention }\end{array}$ & BMIz & $\mathrm{BMIz} \downarrow$ \\
\hline Gatto [52] & 2012 & 104 & 9-11 & Gardening & 12 weeks & $\begin{array}{c}\text { No } \\
\text { intervention }\end{array}$ & $\begin{array}{l}\text { WC } \\
\text { BMI } \\
\text { FVs }\end{array}$ & $\begin{array}{l}\text { WC } \downarrow \\
\mathrm{BMI} \downarrow \\
\mathrm{FVs} \uparrow\end{array}$ \\
\hline Davis [53] & 2021 & 3153 & 9-11 & Gardening & 36 weeks & $\begin{array}{c}\text { No } \\
\text { intervention }\end{array}$ & $\begin{array}{l}\text { BMIz } \\
\text { BMI } \\
\text { WC }\end{array}$ & $\begin{array}{c}\mathrm{BMIz} \uparrow \\
\mathrm{BMI} \uparrow \\
\mathrm{WC} \uparrow\end{array}$ \\
\hline Evans [54] & 2016 & 1600 & $7-9$ & $\begin{array}{c}\text { Gardening } \\
\text { and } \\
\text { Physical } \\
\text { Activity }\end{array}$ & 48 weeks & $\begin{array}{c}\text { No } \\
\text { intervention }\end{array}$ & others & \\
\hline Alexandra [55] & 2020 & 1326 & $9-12$ & $\begin{array}{c}\text { Gardening } \\
\text { and } \\
\text { Physical } \\
\text { Activity }\end{array}$ & 24 weeks & $\begin{array}{c}\text { No } \\
\text { intervention }\end{array}$ & others & \\
\hline
\end{tabular}

\subsection{Quality Assessment}

The results of Cochrane's risk of bias assessment (Figures 2 and 3 ) showed that for most studies, the overall risk of bias was low. Among them, all of the studies (100\%) described the generation of random sequences in detail. In the categories "Timing of identification or recruitment of participants" and "Deviations from the intended interventions", 22 (79\%) trials were assessed as low risk and $6(21 \%)$ trials were assessed as unclear risk, which was related to the lack of accurate information on blinding. The low-risk categories in $64 \%-86 \%$ of the studies were "Selection of the reported result", "Measurement of the outcome", and "Missing outcome data", and the remaining studies were judged to be of unclear risk due to insufficient information on the methods used by researchers to randomly assign participants to groups and in reporting all predefined results. Due to the limited number of studies, it was impossible to explore the existence of publication bias.

\subsection{FVs}

We analyzed the FVs comparison results between the SGA groups and control groups (random model $\mathrm{I}^{2}=96.2 \%$ ). The results showed that FVs in both intervention groups and control groups increased in different degrees, and the difference in added value had statistical significance $(\mathrm{WMD}=0.59, \mathrm{Z}=3.01, p=0.003,95 \% \mathrm{CI}=-0.21 \sim 0.98)$ (Figure 4). The sensitivity analysis outcomes (Supplementary Figure S1) show that the source of heterogeneity is Davis' study.

\subsection{BMI}

Figure 5 shows the comparison results of the BMI between SGA groups and control groups (random model $\mathrm{I}^{2}=86.3 \%$ ). The difference in BMI reduction between the intervention groups and control groups showed no statistical significance (WMD $=-0.49, \mathrm{Z}=0.84$, $p=0.404,95 \% \mathrm{CI}=-1.63-0.65)$. Sensitivity analysis indicated that Davis' study is a source of heterogeneity in BMI combined results (Supplementary Figure S2). 


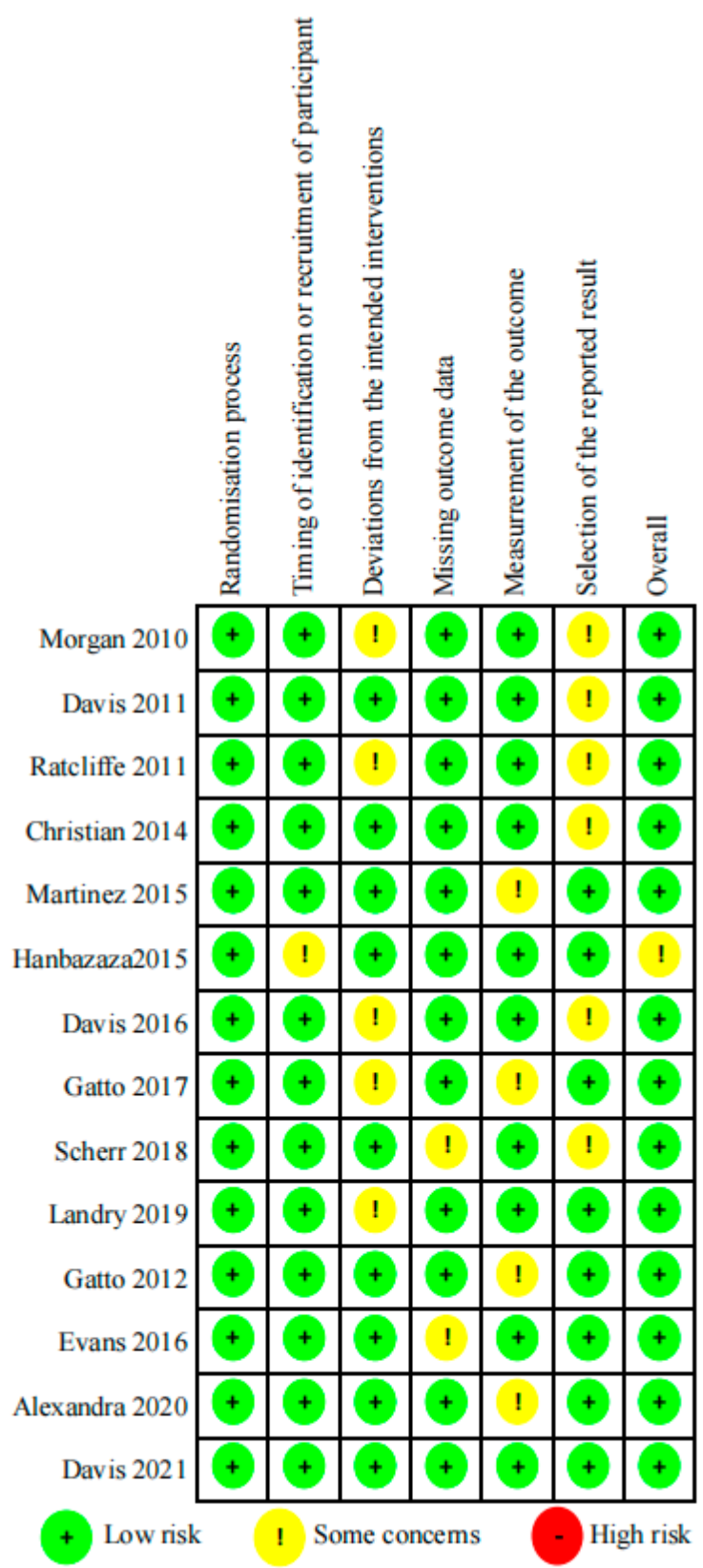

Figure 2. Risk of bias graph per type of bias assessed.

As percentage (intention-to-treat)

Overall Bias

Measurement of the..

Deviations from.

Randomization..

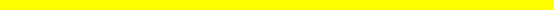

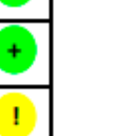




\section{Impact of SGA on children's FVs}

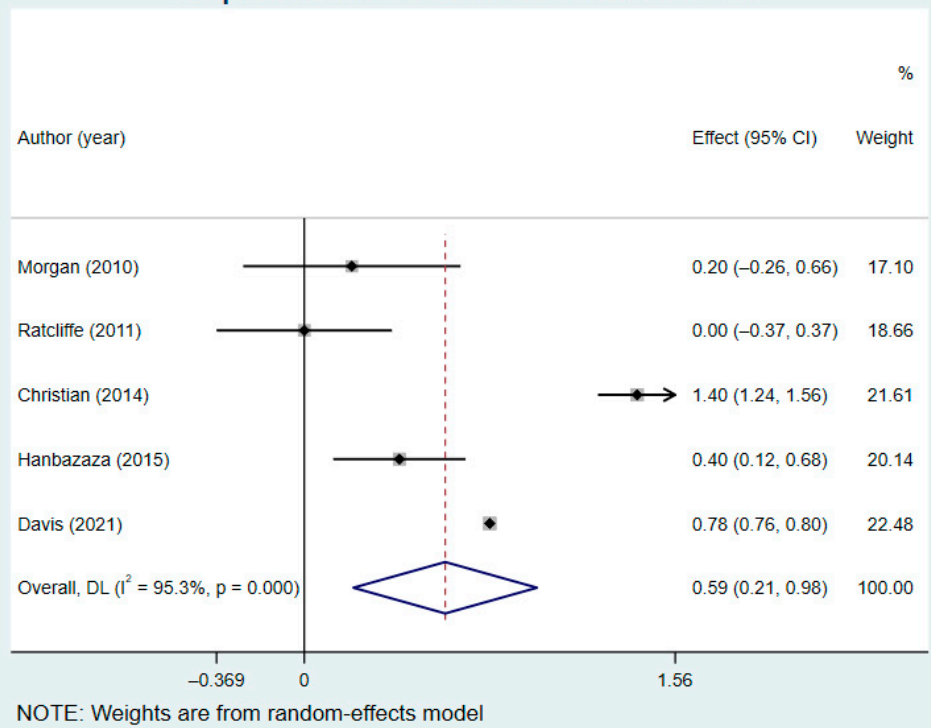

Figure 4. Impact of SGA on children's fruit and vegetable intakes (FVs).

\section{Impact of SGA on children's BMI}

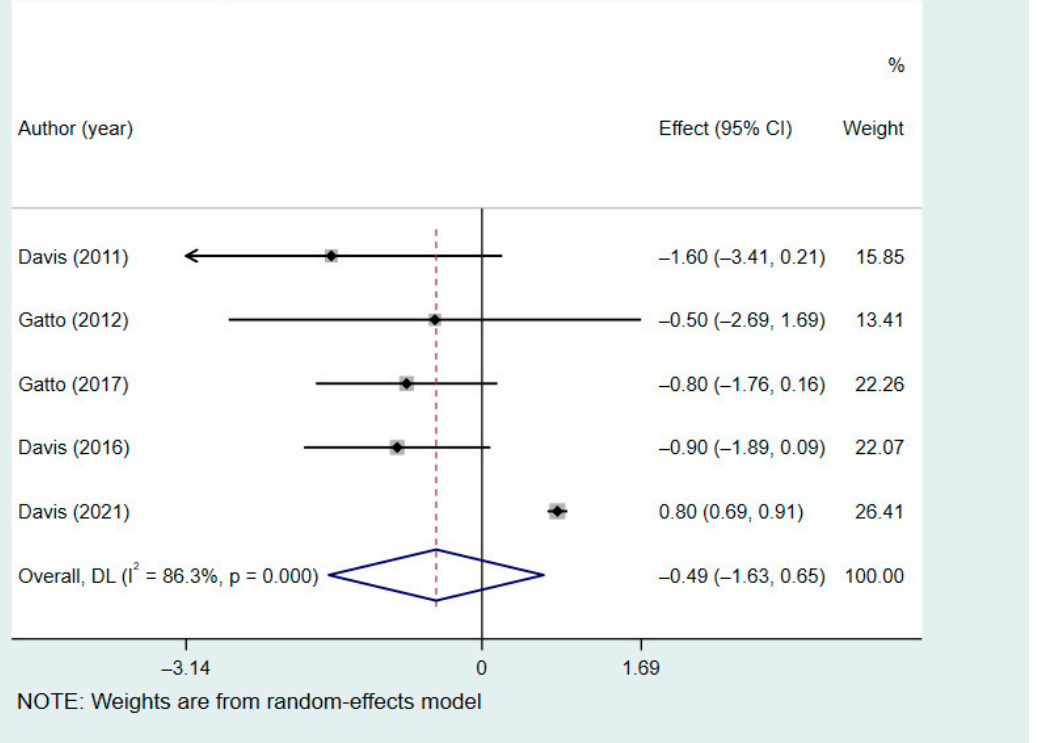

Figure 5. Impact of school gardening activities (SGA) on children's body mass index (BMI).

\subsection{BMI z-Score}

The comparison results of the BMI z-score between the SGA groups and control groups is shown in Figure 6 (random model $\mathrm{I}^{2}=63.0 \%$ ). The results turned out to show that there was no statistical significance in the reduction of the BMI z-score between the intervention groups and control groups (WMD $=-0.12, \mathrm{Z}=1.72, p=0.085,95 \% \mathrm{CI}=-0.26-0.02)$. We carried out a sensitivity analysis (Supplementary Figure S3) and Gatto's study is also a source of heterogeneity in the BMI z-score. 


\section{Impact of SGA on children's BMI Z-score}

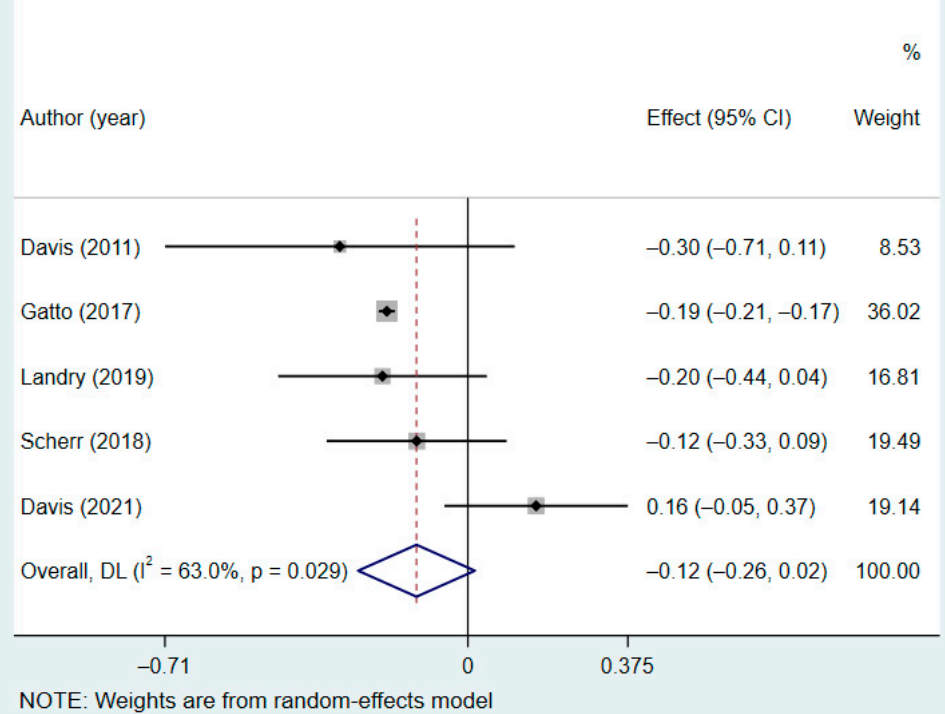

Figure 6. Impact of SGA on children's body mass index z-score (BMI z-score).

\subsection{WC}

We analyzed the comparison results of WC between the SGA intervention groups and control groups (random model $\mathrm{I}^{2}=72.9 \%$ ). The results turned out to show that there was no statistical significance in the reduction of WC between intervention groups and control groups (WMD $=-0.98, \mathrm{Z}=1.19, p=0.235,95 \% \mathrm{CI}=-2.61-0.64$ ) (Figure 7). We carried out sensitivity analysis on all of the six included studies, and the results showed that Gatto's study was the source of heterogeneity in the WC combined results (Supplementary Figure S4).

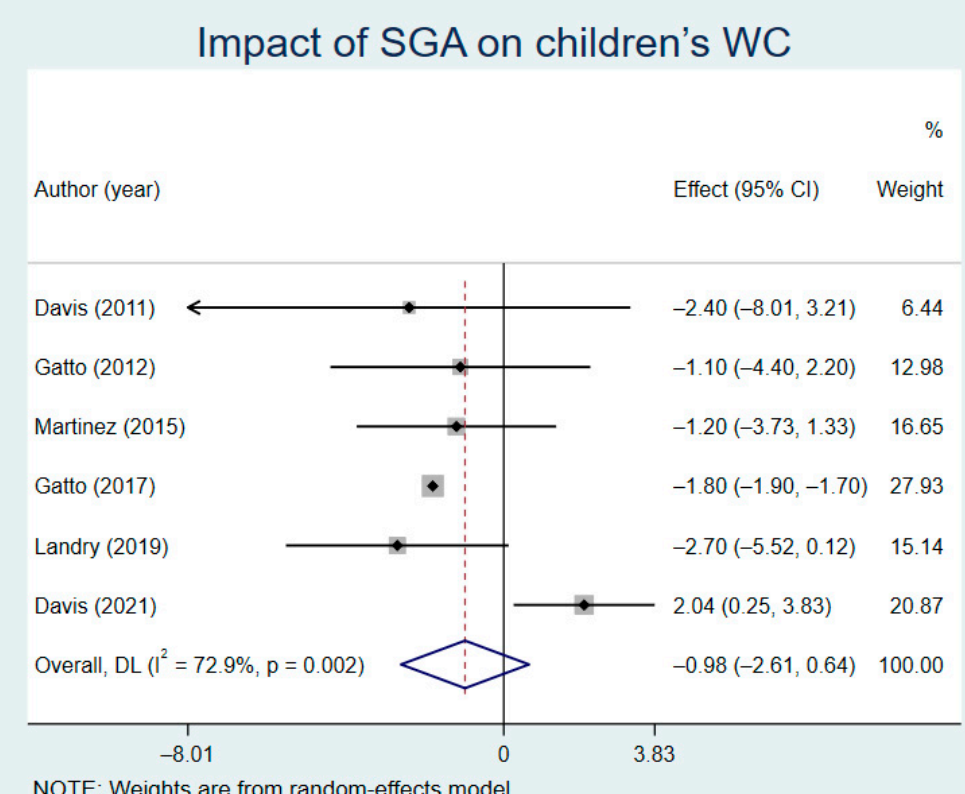

Figure 7. Impact of SGA on children's waist circumference (WC). 


\subsection{Results Impacted by SGA Combined with PA}

A study by Evans et al. [54] set the main outcome as children's BMI alongside other outcomes, such as vegetable intake motivation, vegetable preference, vegetable consumption, sugar-sweetened beverage consumption, and engagement PA. They divided experimental subjects into three intervals according to their BMI index-normal weight, overweight, and obesity - and evaluated the change of obesity by counting the proportion of people in each interval before and after the intervention. The results showed that there was no significant difference in overweight and obesity intervals between the intervention and control group ( $p=0.8)$, and subjects' vegetable intake, intake motivation, and preference in SGA combined with the PA group and the SGA group were significantly improved compared with the control group $(p=0.3)$. Alexandra et al. [55] used the same intervention methods as Evans' [54] to test the accuracy of the research results. After 24 weeks of intervention, they found that vegetable preference in the SGA combined with PA group, as well as in the SGA group, was significantly improved compared to the control group ( $p=0.013$ and $p=0.001$, respectively), especially in regard to vegetable taste $(p=0.000$ and $p=0.000$, respectively) and nutritional knowledge ( $p=0.033, p=0.001$ respectively)". Additionally, compared with the control group, the proportions of overweight and obese subjects in the SGA group $(p=0.039)$ and PA group $(p=0.042)$ were significantly lower, respectively, but there was no significant difference between the SGA combined with PA group and the control group.

The publication bias was assessed by funnel plot and egger's test (Supplementary Figures S5-S16).

\section{Discussion}

This is the first SR and meta-analysis combining SGA with PA to evaluate the changes in the obesity index of children, such as FVs, BMI, BMI z-score, and WC. Since most of the current studies only use an SGA as the main method, more data on the obesity index can be collected. Still, these studies were included in this study for meta-analysis. However, the only two studies using SGA combined with PA as the intervention method have included FVs and other obesity-related outcomes [54,55], which were not unified with those outcomes in the other 12 studies. Thus, they can only be included in this study for SR. Our study shows that SGA and SGA combined with PA can effectively increase children's FVs and improve their fruit and vegetable knowledge, intake motivation, and intake preference. The above-mentioned results are in accordance with previous studies' results $[15,56-59]$ for these outcomes, and highlight this strategy's importance in cultivating children's good eating habits and improving their weight.

The outcomes, such as children's knowledge of fruits and vegetables, intake preference, and intake motivation, could not accurately measure the changes of children's FVs. Therefore, some researchers use a $24 \mathrm{~h}$ food diary (CADET) or Block Kids food filter to measure the changes of FVs in portions [23,25,26,47,53]. Among them, Christian's [23] and Davis' [53] studies had the most significant effects and showed an increase in the children's FVs by about 1.4 and 0.8 portions through 72 weeks and 36 weeks of SGA and other interventions, respectively. While in Morgan's [26] and Hanbazaza's [47] studies, after 10 and 72 weeks of SGA, the FVs increased only by 0.2 and 0.4 portions, respectively. The reasons for this difference may be as follows. Christian [23] strengthened the role of parents in SGA. Parents not only participated in part of the curriculum of the SGA, but were also supervising their children to fill in the CADET, which improved the results helpfully. Professional gardening experts were used in Davis' [53] study as interveners who conducted SGA for children with cooking activities and nutrition education as auxiliary means, which effectively enhanced children's FVs. The short intervention time of Morgan's [26] and Ratcliffe's [25] studies may have affected the outcomes. Although Hanbazaza [47] also conducted a 72-week SGA, the frequency of intervention and parental participation was low, which may be an important reason for limiting an effective improvement of the 
outcomes. However, the above studies have confirmed that SGA has a positive effect on improving children's FVs.

The meta-analysis of anthropometric outcomes related to obesity showed that the BMI, BMI z-score, and WC were all reduced to varying degrees after the intervention. A recent study [53] with an expanded sample size and more rigorous statistics found that SGA had no obvious effect on the three outcomes. Therefore, we concluded that overall results indicated that SGA had no significant effect on improving children's obesity. The World Health Organization (WHO) has analyzed the possibility and scientific validity of using BMI, WC, and the Waist-Hip Ratio to predict chronic diseases [15]. Additionally, the decrease in BMI and WC after intervention in some studies $[22,27,48-50,52,60]$ indicated that SGA has a positive effect on the prevention and improvement of some chronic diseases in children, even if the improvement effect is limited. Among them, five studies $[22,27,48,50,53]$ added cooking intervention into SGA, namely cooking demonstrations and having children cook vegetables and fruits planted by themselves. The results showed that compared with the outcomes of those only intervened by SGA, the BMI and WC outcomes of those intervened by both cooking intervention and SGA reduced more significantly. For example, Davis et al. [53] added cooking demonstrations and other activities to the SGA and made them into the LA Sprouts' course. The results showed that the BMI and WC of children in the LA Sprouts' course group decreased more significantly than the SGA group or cooking intervention group separately. This coincided with the conclusion that SGA combined with nutrition education could more effectively prevent child obesity. Both proved that combined interventions can achieve more effective effects [16,51], which provides new ideas for improving the health of obese children. The results of the meta-analysis indicated that interventions based only on SGA had no significant impact on children's BMI and WC. In other words, a single intervention such as gardening or cooking has limited effect on improving childhood obesity, so we should consider combing SGA with other interventions in the future to explore its effectiveness in improving overweight and obesity in children.

As highlighted by Katz et al. [16,61], the $6 \mathrm{~h}$ that school-aged children spend at school every day, for more than half the year, constitute a substantial part of their time and their lives. Therefore, it is important to consider school as one of the major drivers and elective settings for children's education on healthy lifestyles [62,63]. Recently, more studies have shown that physical activities provide many benefits in regulating metabolism and weight loss by increasing energy consumption and improving metabolic status [64-68], so more attention was paid to physical exercise-related courses in the program of preventing childhood obesity. In theory, SGA paired with PA can improve the children's FVs and their PA, making it more successful in reducing obesity in children.

There are only two studies on SGA combined with PA, but these two studies only measured children's intake of vegetables without the intake of fruits. This may be because vegetables are relatively easy to grow and harvest. In addition, the two studies only measured the proportion of people in different weight intervals in anthropometrics, which may be related to the difficulty in collecting data of the large sample size selected in the study. Evans et al. [54] conducted a 48-week SGA combined with PA and found that children's preference for vegetable intake increased significantly, but the BMI outcome showed that the number of overweight and obese children did not significantly decrease. Since the sample size selected by the researcher was relatively large and the samples were distributed in 28 schools, it was difficult to carry out the intervention and balance all conditions. However, this combination of SGA and PA is an innovation. On this basis, Alexandra et al. [55] did their study with the same intervention method. Additionally, the results showed that both the SGA group and SGA combined with the PA group effectively improved children's vegetable-related outcomes. Both the SGA group and PA group effectively improved childhood obesity. However, the SGA combined with PA had no obvious effect on improving childhood obesity, which may be related to the implementation of the intervention. Because the curriculum executors of the SGA combined with the PA group were not teachers but trainers, the implementation of the intervention may lack 
scientific validity and rationality. In addition, these two studies both used low-intensity PA. However, many studies have shown that compared to low-intensity PA, MVPA has a significant effect on reducing obese children's BMI, WC, and other outcomes [69-73]. In future studies, MVPA should be combined with SGA, and the obesity outcomes, such as WC and blood pressure, should be added to more comprehensively detect the accuracy of obesity improvement, which provides a new perspective and ideas for future studies.

This study has the following limitations. First, although the number of studies on SGA has steadily increased in the last 10 years, there were few comprehensive studies on SGA combined with PA, which should be explored in the future. Second, FVs-related outcomes in most studies $[23,25,26,47,53]$ were measured by self-report, which is easily affected by social recognition bias, so they may not accurately represent the changes in dietary intake. Thirdly, there are little data on long-term changes of FVs, so we were unable to determine if the changes of FVs continued over time, and further research is needed. Finally, the main purpose of gardening-based interventions is to improve children's intake of fruits and vegetables. Therefore, the literature included in this study only analyzed changes in fruit and vegetable intake. In future studies, we can also observe whether unhealthy eating behaviors related to childhood obesity have improved, such as excess intake of sugar-sweetened beverages, desserts, and fried foods.

\section{Conclusions}

The intervention based on SGA can effectively increase children's FVs and improve their intake motivation, attitude, and preference for vegetables and fruits, but it has no obvious effect on reducing BMI outcomes and WC. The increase in both FVs and PA has obvious effects on the improvement of childhood obesity. In future studies, we should consider integrating various interventions such as SGA, PA, and cooking. Additionally, we can reasonably learn from and innovate the research design of previous scholars and formulate more scientific research plans to explore methods that are more conducive to improving childhood obesity.

Supplementary Materials: The following are available online at https:/ /www.mdpi.com/article/10 $.3390 /$ nu13082605/s1. Table S1. PRISMA checklist; Table S2. Database search formulas (example for two databases); Figures S1-S4. Sensitivity analysis outcomes; Figures S5-S12. Funnel plot outcomes; Figure S13-S16. Egger's test and Egger's test data outcomes.

Author Contributions: Y.Q. contributed to the evaluation and interpretation of data, and the writing the first drafts and the final version of this manuscript. H.W. contributed to scrub data and maintain research data for initial use and later re-use. Y.X. contributed to the statistical analysis of data and participated in the interpretation and synthesis of data. E.G. contributed to the polishing and modified the format of the manuscript. M.S. contributed to application of statistical to analyze or synthesize study data. S.R. contributed to verification of the overall replication of results and other research outputs. Q.L. and S.H.H. contributed to the development of the review concept and critically reviewed the manuscript. All authors have read and agreed to the published version of the manuscript.

Funding: This research was funded by the Social Science Foundation Education Special Project of Hunan Province in 2021, grant number: 21YBJ24.

Institutional Review Board Statement: Not applicable.

Informed Consent Statement: Not applicable.

Data Availability Statement: Data are contained within the paper.

Acknowledgments: The authors express great appreciation to the Social Science Foundation Education Special Project of Hunan Province and Central South University in Changsha, China for their funding support in carrying out this survey.

Conflicts of Interest: The authors declare no conflict of interest. 


\section{References}

1. Ng, M.; Fleming, T.; Robinson, M.; Thomson, B.; Graetz, N.; Margono, C.; Mullany, E.C.; Biryukov, S.; Abbafati, C.; Abera, S.F.; et al. Global, regional, and national prevalence of overweight and obesity in children and adults during 1980-2013: A systematic analysis for the Global Burden of Disease Study 2013. Lancet 2014, 384, 766-781. [CrossRef]

2. Wang, Y.; Lobstein, T. Worldwide trends in childhood overweight and obesity. Int. J. Pediatr. Obes. 2006, 1, 11-25. [CrossRef]

3. Ogden, C.L.; Carroll, M.D.; Kit, B.K.; Flegal, K.M. Prevalence of childhood and adult obesity in the United States, 2011-2012. JAMA 2014, 311, 806-814. [CrossRef] [PubMed]

4. Jie, G.A.Q.J. Interpretation of the 2017 U.S. Preventive Services Working Group's Recommendations for Screening Obesity in Children and Adolescents. J. Chin. Gen. Pract. 2017, 20, 3195-3198.

5. National Center for Health Statistics. U.S. Health, United States, 2011: With Special Features on Socioeconomic Status and Health. National Center for Health Statistics: Hyattsville, MD, USA, 2012. Available online: https://www.ncbi.nlm.nih.gov/books/ NBK98752/ (accessed on 27 July 2021).

6. Pan, X.F.; Wang, L.M.; Pan, A. Epidemiology and determinants of obesity in China. Lancet Diabetes Endocrinol. $2021,9,373-392$. [CrossRef]

7. Serdula, M.K. Do obese children become obese adults? A review of the literature. Prev. Med. 1993, 22, 167-177. [CrossRef]

8. Liu, W.; Li, Q.; Li, H.; Li, J.; Wang, H.J.; Li, B. 20-year trends in prevalence of overweight and obesity among children aged 0-6 in Harbin, China: A multiple cross-sectional study. PLoS ONE 2018, 13, e0198032. [CrossRef]

9. Micic, D.D.; Polovina, S.; Micic, D.D. Does Obesity Cause Type 2 Diabetes? Int. C Interd. Manag. D 2020, 11, 379-381.

10. Liang, Y.J.; Hou, D.Q.; Zhao, X.Y.; Wang, L.; Hu, Y.H.; Liu, J.T.; Cheng, H.; Yang, P.Y.; Shan, X.K.; Yan, Y.; et al. Childhood obesity affects adult metabolic syndrome and diabetes. Endocrine 2015, 50, 87-92. [CrossRef]

11. Beilin, L.; Huang, R.C. Childhood obesity, hypertension, the metabolic syndrome and adult cardiovascular disease. Clin. Exp. Pharm. Physiol. 2008, 35, 409-411. [CrossRef]

12. Burgess, J.A.; Walters, E.H.; Byrnes, G.B.; Jenkins, M.A.; Giles, G.G.; Abramson, M.J.; Hopper, J.L.; Dharmage, S.C. Childhood obesity predicts current incident asthma in adult women. Thorax 2005, 60, Ii32-Ii33.

13. Loke, K.Y. Early Influences in Childhood Obesity Implications for Adult Metabolic Disease. Ann. Acad. Med. Singap. 2014, 43, 57-58.

14. Wang, Z.Q.; Peng, Y.; Liu, M.N. Age Variation in the Association Between Obesity and Mortality in Adults. Obesity 2017, 25, 2137-2141. [CrossRef]

15. Nolan, G.A.; McFarland, A.L.; Zajicek, J.M.; Waliczek, T.M. The Effects of Nutrition Education and Gardening on Attitudes, Preferences, and Knowledge of Minority Second to Fifth Graders in the Rio Grande Valley Toward Fruit and Vegetables. Horttechnology 2012, 22, 299-304. [CrossRef]

16. Langellotto, G.A.; Gupta, A. Gardening Increases Vegetable Consumption in School-aged Children: A Meta-analytical Synthesis. Horttechnology 2012, 22, 430-445. [CrossRef]

17. Rosenstock, I.M.; Strecher, V.J.; Becker, M.H. Social learning theory and the Health Belief Model. Health Educ. Q. 1988, 15, 175-183. [CrossRef] [PubMed]

18. Ozer, E.J. The effects of school gardens on students and schools: Conceptualization and considerations for maximizing healthy development. Health Educ. Behav. 2007, 34, 846-863. [CrossRef] [PubMed]

19. Christian, M.S.; Evans, C.E.L.; Conner, M.; Ransley, J.K.; Cade, J.E. Study protocol: Can a school gardening intervention improve children's diets? BMC Public Health 2012, 12, 304. [CrossRef]

20. Molitor, F.; Doerr, C. Dietary Behaviors and Obesity of Children From Low-Income Households by Gender of Caregiver and Child. Am. J. Health Promot. 2021, 35, 434-437. [CrossRef]

21. Savage, J.S.; Fisher, J.O.; Birch, L.L. Parental influence on eating behavior: Conception to adolescence. J. Law Med. Ethics. 2007, 35, 22-34. [CrossRef]

22. Davis, J.N.; Ventura, E.E.; Cook, L.T.; Gyllenhammer, L.E.; Gatto, N.M. LA Sprouts: A Gardening, Nutrition, and Cooking Intervention for Latino Youth Improves Diet and Reduces Obesity. J. Am. Diet. Assoc. 2011, 111, 1224-1230. [CrossRef]

23. Christian, M.S.; El Evans, C.; Nykjaer, C.; Hancock, N.; Cade, J.E. Evaluation of the impact of a school gardening intervention on children's fruit and vegetable intake: A randomised controlled trial. Int. J. Behav. Nutr. Phy. 2014, 11, 99. [CrossRef]

24. Castro, D.C.; Samuels, M.; Harman, A.E. Growing Healthy Kids A Community Garden-Based Obesity Prevention Program. Am. J. Prev. Med. 2013, 44, S193-S199. [CrossRef]

25. Ratcliffe, M.M.; Merrigan, K.A.; Rogers, B.L.; Goldberg, J.P. The effects of school garden experiences on middle school-aged students' knowledge, attitudes, and behaviors associated with vegetable consumption. Health Promot. Pract. 2011, $12,36-43$. [CrossRef]

26. Morgan, P.J.; Warren, J.M.; Lubans, D.R.; Saunders, K.L.; Quick, G.I.; Collins, C.E. The impact of nutrition education with and without a school garden on knowledge, vegetable intake and preferences and quality of school life among primary-school students. Public. Health Nutr. 2010, 13, 1931-1940. [CrossRef] [PubMed]

27. Gatto, N.M.; Martinez, L.C.; Spruijt-Metz, D.; Davis, J.N. LA sprouts randomized controlled nutrition, cooking and gardening programme reduces obesity and metabolic risk in Hispanic/Latino youth. Pediatr. Obes. 2017, 12, 28-37. [CrossRef]

28. Utter, J.; Denny, S.; Dyson, B. School gardens and adolescent nutrition and BMI: Results from a national, multilevel study. Prev. Med. 2016, 83, 1-4. [CrossRef] [PubMed] 
29. Liang, J.; Lu, B.; Hao, L. Effect of resistance training on body composition, blood lipids and serum leptin of obese children. J. Chin. Sch. Health 2017, 38, 1379-1381+1384.

30. Liang, J.a.L.H. Effects of high intensity intermittent exercise on body composition, blood pressure and serum Chemerin in obese children. J. Chin. Sch. Health 2018, 39, 1729-1732.

31. Jeyanthi, S.; Arumugam, N.; Parasher, R.K. Effect of physical exercises on attention, motor skill and physical fitness in children with attention deficit hyperactivity disorder: A systematic review. Atten. Defic Hyperact. Disord. 2019, 11, 125-137. [CrossRef]

32. Ng, Q.X.; Ho, C.Y.X.; Chan, H.W.; Yong, B.Z.J.; Yeo, W.S. Managing childhood and adolescent attention-deficit/hyperactivity disorder (ADHD) with exercise: A systematic review. Complement Ther. Med. 2017, 34, 123-128. [CrossRef] [PubMed]

33. Contreras-Osorio, F.; Campos-Jara, C.; Martinez-Salazar, C.; Chirosa-Rios, L.; Martinez-Garcia, D. Effects of Sport-Based Interventions on Children's Executive Function: A Systematic Review and Meta-Analysis. Brain Sci. 2021, 11, 755. [CrossRef]

34. Ganjeh, P.; Meyer, T.; Hagmayer, Y.; Kuhnert, R.; Ravens-Sieberer, U.; von Steinbuechel, N.; Rothenberger, A.; Becker, A. Physical Activity Improves Mental Health in Children and Adolescents Irrespective of the Diagnosis of Attention Deficit Hyperactivity Disorder (ADHD)-A Multi-Wave Analysis Using Data from the KiGGS Study. Int. J. Environ. Res. Public Health 2021, $18,2207$. [CrossRef] [PubMed]

35. Story, M. School-based approaches for preventing and treating obesity. Int. J. Obesity 1999, 23, S43-S51. [CrossRef]

36. Flattum, C.; Friend, S.; Story, M.; Neumark-Sztainer, D. Evaluation of an Individualized Counseling Approach as Part of a Multicomponent School-Based Program to Prevent Weight-Related Problems among Adolescent Girls. J. Am. Diet. Assoc. 2011, 111, 1218-1223. [CrossRef] [PubMed]

37. Basch, C.E. Physical Activity and the Achievement Gap Among Urban Minority Youth. J. Sch. Health 2011, 81, 626-634. [CrossRef]

38. Rausch, J.C.; Berger-Jenkins, E.; Nieto, A.R.; McCord, M.; Meyer, D. Effect of a School-Based Intervention on Parents' Nutrition and Exercise Knowledge, Attitudes, and Behaviors. Am. J. Health Educ. 2015, 46, 33-39. [CrossRef]

39. Grasten, A. School-based physical activity interventions for children and youth: Keys for success. J. Sport Health Sci. 2017, 6, 290-291. [CrossRef]

40. Messiah, S.E.; Arheart, K.L.; Lipshultz, S.E.; Miller, T.L. Body mass index, waist circumference, and cardiovascular risk factors in adolescents. J. Pediatr. 2008, 153, 845-850. [CrossRef]

41. Messiah, S.E. BMI, waist circumference, and selected cardiovascular disease risk factors among preschool-age children. Obesity 2012, 20, 1942-1949. [CrossRef]

42. Magnussen, C.G.; Koskinen, J.; Chen, W.; Thomson, R.; Schmidt, M.D.; Srinivasan, S.R.; Kivimaki, M.; Mattsson, N.; Kahonen, M.; Laitinen, T.; et al. Pediatric Metabolic Syndrome Predicts Adulthood Metabolic Syndrome, Subclinical Atherosclerosis, and Type 2 Diabetes Mellitus but Is No Better Than Body Mass Index Alone The Bogalusa Heart Study and the Cardiovascular Risk in Young Finns Study. Circulation 2010, 122, 1604-U1134. [CrossRef]

43. Soltero, E.G.; Parker, N.H.; Mama, S.K.; Ledoux, T.A.; Lee, R.E. Lessons Learned from Implementing of Garden Education Program in Early Child Care. Health Promot. Pract. 2021, 22, 266-274. [CrossRef] [PubMed]

44. Kegler, M.C.; Prakash, R.; Hermstad, A.; Williamson, D.; Anderson, K.; Haardorfer, R. Home gardening and associations with fruit and vegetable intake and BMI. Public Health Nutr. 2020, 23, 3417-3422. [CrossRef]

45. Skelton, K.; Herbert, A.; Benjamin-Neelon, S.E. Garden-based interventions and early childhood health: A protocol for an umbrella review. Syst. Rev. 2019, 8, 310. [CrossRef]

46. Moher, D.; Shamseer, L.; Clarke, M.; Ghersi, D.; Liberati, A.; Petticrew, M.; Shekelle, P.; Stewart, L.A.; Grp, P.-P. Preferred reporting items for systematic review and meta-analysis protocols (PRISMA-P) 2015 statement. Syst. Rev. 2015, 4, 1. [CrossRef]

47. Hanbazaza, M.A.; Triador, L.; Ball, G.D.C.; Farmer, A.; Maximova, K.; Nation, A.F.; Willows, N.D. The Impact of School Gardening on Cree Children's Knowledge and Attitudes toward Vegetables and Fruit. Can. J. Diet. Pract. Res. 2015, 76, 133-139. [CrossRef] [PubMed]

48. Davis, J.N.; Martinez, L.C.; Spruijt-Metz, D.; Gatto, N.M. LA Sprouts: A 12-Week Gardening, Nutrition, and Cooking Randomized Control Trial Improves Determinants of Dietary Behaviors. J. Nutr. Educ. Behav. 2016, 48, 2-11.e11. [CrossRef] [PubMed]

49. Landry, M.J.; Markowitz, A.K.; Asigbee, F.M.; Gatto, N.M.; Spruijt-Metz, D.; Davis, J.N. Cooking and Gardening Behaviors and Improvements in Dietary Intake in Hispanic/Latino Youth. Child. Obes. 2019, 15, 262-270. [CrossRef]

50. Martinez, L.C.; Gatto, N.M.; Spruijt-Metz, D.; Davis, J.N. Design and methodology of the LA Sprouts nutrition, cooking and gardening program for Latino youth: A randomized controlled intervention. Contemp. Clin. Trials 2015, 42, 219-227. [CrossRef]

51. Scherr, R.E.; Linnell, J.D.; Dharmar, M.; Beccarelli, L.M.; Bergman, J.J.; Briggs, M.; Brian, K.M.; Feenstra, G.; Hillhouse, J.C.; Keen, C.L.; et al. A Multicomponent, School-Based Intervention, the Shaping Healthy Choices Program, Improves NutritionRelated Outcomes. J. Nutr. Educ. Behav. 2017, 49, 368-379.e1. [CrossRef] [PubMed]

52. Gatto, N.M.; Ventura, E.E.; Cook, L.T.; Gyllenhammer, L.E.; Davis, J.N. LA Sprouts: A garden-based nutrition intervention pilot program influences motivation and preferences for fruits and vegetables in Latino youth. J. Acad. Nutr. Diet. 2012, 112, 913-920. [CrossRef] [PubMed]

53. Davis, J.N.; Perez, A.; Asigbee, F.M.; Landry, M.J.; Vandyousefi, S.; Ghaddar, R.; Hoover, A.; Jeans, M.; Nikah, K.; Fischer, B.; et al. School-based gardening, cooking and nutrition intervention increased vegetable intake but did not reduce BMI: Texas sprouts-a cluster randomized controlled trial. Int. J. Behav. Nutr. Phy. 2021, 18, 18. [CrossRef] [PubMed] 
54. Evans, A.; Ranjit, N.; Hoelscher, D.; Jovanovic, C.; Lopez, M.; McIntosh, A.; Ory, M.; Whittlesey, L.; McKyer, L.; Kirk, A.; et al. Impact of school-based vegetable garden and physical activity coordinated health interventions on weight status and weightrelated behaviors of ethnically diverse, low-income students: Study design and baseline data of the Texas, Grow! Eat! Go! (TGEG) cluster-randomized controlled trial. BMC Public. Health 2016, 16, 973. [CrossRef]

55. Van den Berg, A.; Warren, J.L.; McIntosh, A.; Hoelscher, D.; Ory, M.G.; Jovanovic, C.; Lopez, M.; Whittlesey, L.; Kirk, A.; Walton, C.; et al. Impact of a Gardening and Physical Activity Intervention in Title 1 Schools: The TGEG Study. Child. Obes. 2020, 16, S44-S54. [CrossRef]

56. Knapp, M.B.; Hall, M.T.; Mundorf, A.R.; Partridge, K.L.; Johnson, C.C. Perceptions of School-Based Kitchen Garden Programs in Low-Income, African American Communities. Health Promot. Pract. 2019, 20, 667-674. [CrossRef] [PubMed]

57. Leuven, J.R.F.W.; Rutenfrans, A.H.M.; Dolfing, A.G.; Leuven, R.S.E.W. School gardening increases knowledge of primary school children on edible plants and preference for vegetables. Food Sci. Nutr. 2018, 6, 1960-1967. [CrossRef] [PubMed]

58. Taylor, C.; Symon, E.B.; Dabbs, A.; Way, A.; Thompson, O.M. Assessing a School Gardening Program as an Integrated Component of a Pilot Farm-to-school Initiative Based in South Carolina. Horttechnology 2017, 27, 228-234. [CrossRef]

59. Schreinemachers, P.; Bhattarai, D.R.; Subedi, G.D.; Acharya, T.P.; Chen, H.P.; Yang, R.Y.; Kashichhawa, N.K.; Dhungana, U.; Luther, G.C.; Mecozzi, M. Impact of school gardens in Nepal: A cluster randomised controlled trial. J. Dev. Effect. 2017, 9, 329-343. [CrossRef]

60. Nishida, C.; Ko, G.T.; Kumanyika, S. Body fat distribution and noncommunicable diseases in populations: Overview of the 2008 WHO Expert Consultation on Waist Circumference and Waist-Hip Ratio. Eur. J. Clin. Nutr. 2010, 64, 2-5. [CrossRef]

61. Blair, D. The Child in the Garden: An Evaluative Review of the Benefits of School Gardening. J. Environ. Educ. 2009, 40, 15-38. [CrossRef]

62. Katz, D.L.; O'Connell, M.; Njike, V.Y.; Yeh, M.C.; Nawaz, H. Strategies for the prevention and control of obesity in the school setting: Systematic review and meta-analysis. Int. J. Obes. 2008, 32, 1780-1789. [CrossRef]

63. Katz, D.L. School-Based Interventions for Health Promotion and Weight Control: Not Just Waiting on the World to Change. Annu. Rev. Publ. Health 2009, 30, 253-272. [CrossRef] [PubMed]

64. Gonzalez-Suarez, C.; Worley, A.; Grimmer-Somers, K.; Dones, V. School-Based Interventions on Childhood Obesity A MetaAnalysis. Am. J. Prev. Med. 2009, 37, 418-427. [CrossRef]

65. McGuire, S. Institute of Medicine. 2012. Accelerating Progress in Obesity Prevention: Solving the Weight of the Nation. Washington, DC: The National Academies Press. Adv. Nutr. 2012, 3, 708-709. [CrossRef] [PubMed]

66. Sa, G.D.; Neves, V.D.; Fraga, S.R.D.; Souza-Mello, V.; Barbosa-da-Silva, S. High-intensity interval training has beneficial effects on cardiac remodeling through local renin-angiotensin system modulation in mice fed high-fat or high-fructose diets. Life Sci. 2017, 189, 8-17. [CrossRef]

67. Smith, K.E.; Mason, T.B.; O'Connor, S.M.; Wang, S.; Dzubur, E.; Crosby, R.D.; Wonderlich, S.A.; Salvy, S.J.; Feda, D.M.; Roemmich, J.N. Bi-Directional Associations Between Real-Time Affect and Physical Activity in Weight-Discordant Siblings. J. Pediatr. Psychol 2021, 46, 443-453. [CrossRef] [PubMed]

68. Paduano, S.; Greco, A.; Borsari, L.; Salvia, C.; Tancredi, S.; Pinca, J.; Midili, S.; Tripodi, A.; Borella, P.; Marchesi, I. Physical and Sedentary Activities and Childhood Overweight/Obesity: A Cross-Sectional Study among First-Year Children of Primary Schools in Modena, Italy. Int. J. Environ. Res. Public Health 2021, 18, 3221. [CrossRef]

69. Imierska, M.; Kurianiuk, A.; Blachnio-Zabielska, A. The Influence of Physical Activity on the Bioactive Lipids Metabolism in Obesity-Induced Muscle Insulin Resistance. Biomolecules 2020, 10, 1665. [CrossRef] [PubMed]

70. Pysna, J.; Pysny, L.; Cihlar, D.; Petru, D.; Skopek, M. Effect of Physical Activity on Obesity in Second Stage Pupils of Elementary Schools in Northwest Bohemia. Sustainability 2020, 12, 42. [CrossRef]

71. Smith, K.E.; O'Connor, S.M.; Mason, T.B.; Wang, S.; Dzubur, E.; Crosby, R.D.; Wonderlich, S.A.; Salvy, S.J.; Feda, D.M.; Roemmich, J.N. Associations between objective physical activity and emotional eating among adiposity-discordant siblings using ecological momentary assessment and accelerometers. Pediatr. Obes. 2021, 16, e12720. [CrossRef] [PubMed]

72. Schwarzfischer, P.; Gruszfeld, D.; Stolarczyk, A.; Ferre, N.; Escribano, J.; Rousseaux, D.; Moretti, M.; Mariani, B.; Verduci, E.; Koletzko, B.; et al. Physical Activity and Sedentary Behavior From 6 to 11 Years. Pediatrics 2019, 143, e20180994. [CrossRef] [PubMed]

73. Riso, E.M.; Kull, M.; Mooses, K.; Jurimae, J. Physical activity, sedentary time and sleep duration: Associations with body composition in 10-12-year-old Estonian schoolchildren. BMC Public Health 2018, 18, 496. [CrossRef] [PubMed] 